\title{
Article \\ Sustainable Production of Glycolipids by Biocatalyst on Renewable Deep Eutectic Solvents
}

\author{
Laura V. Hoyos ${ }^{1}$, Laura Ramírez ${ }^{1}$, Cristhian J. Yarce ${ }^{2}$ (D) Carlos Alvarez-Vasco ${ }^{1,3}$ and Nelson H. Caicedo Ortega ${ }^{1,3, * \mathbb{D}}$ \\ 1 Departamento de Ingeniería Bioquímica, Facultad de Ingeniería, Universidad ICESI, Calle 18 No. 122-135, \\ Cali 760035, Colombia; valentina.hoyos99@gmail.com (L.V.H.); lauravanessaramirez@hotmail.com (L.R.); \\ caalvarez@icesi.edu.co (C.A.-V.) \\ 2 Laboratorio de Diseño y Formulación de Productos Químicos y Derivados, Departamento de Ciencias \\ Farmacéuticas, Facultad de Ciencias Naturales, Universidad ICESI, Calle 18 No. 122-135, \\ Cali 760035, Colombia; cjyarce@icesi.edu.co \\ 3 Centro BioInc, Universidad ICESI, Calle 18 No. 122-135, Cali 760035, Colombia \\ * Correspondence: nhcaicedo@icesi.edu.co; Tel.: +57-318-754-8041
}

Citation: Hoyos, L.V.; Ramírez, L.;

Yarce, C.J.; Alvarez-Vasco, C.; Caicedo Ortega, N.H. Sustainable Production of Glycolipids by Biocatalyst on Renewable Deep Eutectic Solvents. Catalysts 2021, 11, 853. https:// doi.org/10.3390/catal11070853

Academic Editor: Sudhir Ravula

Received: 13 June 2021

Accepted: 2 July 2021

Published: 16 July 2021

Publisher's Note: MDPI stays neutral with regard to jurisdictional claims in published maps and institutional affiliations.

Copyright: (c) 2021 by the authors. Licensee MDPI, Basel, Switzerland. This article is an open access article distributed under the terms and conditions of the Creative Commons Attribution (CC BY) license (https:/ / creativecommons.org/licenses/by/ $4.0 /)$

\begin{abstract}
Glycolipids have become an ecofriendly alternative to chemically obtained surfactants, mainly for the cosmetic, pharmaceutical, and food industries. However, the sustainable production of these compounds is still challenging, because: $(i)$ water is a recognized inhibitor, (ii) multiphases make the use of cosolvent reaction medium necessary, and (iii) there are difficulties in finding a source for both starting materials. This study used sugars and lipids from peach palm fruit shells or model compounds as substrates to synthesize glycolipids on five different renewable deep eutectic solvents (Re-DES) alone or with a cosolvent system. Substrate conversions up to $24.84 \%$ (so far, the highest reported for this reaction on DES), showing (1) the non-precipitation of glucose in the solvent, (2) emulsification and (3) low viscosity (e.g., more favorable mass transfer) as the main limiting factors for these heterogeneous enzymatic processes. The resulting conversion was reached using a cosolvent system Re-DES:DMSO:t-butanol that was robust enough to allow conversions in the range 19-25\%, using either model compounds or sugar and fatty acid extracts, with free or immobilized enzymes. Finally, the characterization of the in-house synthesized glycolipids by surface tension demonstrated their potential as biosurfactants, for instance, as an alternative to alcohol ethoxylates, industrially produced using less sustainable methods.
\end{abstract}

Keywords: glycolipids; deep eutectic solvents; peach palm fruit shells; biocatalyst; cosolvent system

\section{Introduction}

By 2023, global biosurfactant sales are expected to reach USD 2.8 billion [1]. The growing interest in these molecules is due to their surface activity and emulsifying capacity; characteristics that, added to their low toxicity and high biodegradability, make biosurfactants a promising alternative to chemically obtained surfactants.

Due to their broad applicability, glycolipids represent a large part of the biosurfactant market. Their properties depend on the lengths, ramifications, sugars and fatty acid bonds that compose them. Furthermore, these odorless, tasteless, and non-irritating molecules can be used in the cosmetic, food, or pharmaceutical industry [2].

Glycolipids are synthesized through an enzymatic reaction using lipases (triacylglycerol hydrolase; E.C.\# 3.1.1.3) as catalysts of two possible routes: esterification [3,4] or transesterification $[5,6]$. It is necessary to limit water content in the reaction media to promote glycolipid formation over its hydrolysis, due to lipases hydrolytic nature. Therefore, transesterification is more convenient since no water is formed as a by-product, and consequently, dehydration of the reaction media is avoided throughout the process. Additionally, to favor the synthesis, several options of anhydrous media have been explored [7].

Deep eutectic solvents (DESs) are among the most promising reaction media because they are biodegradable, non-toxic, non-volatile and environmentally friendly [8,9]. In 
contrast to other anhydrous solvents (e.g., organic solvents or ionic liquids), DESs can solubilize carbohydrates, and if synthesized from sugars, they can act simultaneously as substrate and solvent $[5,10]$. In addition, DESs share many features of conventional ionic liquids, yet DES components are often cheaper, biodegradable, and safer to the environment $[11,12]$. However, low yields have been obtained in the production of glycolipids in DESs, usually associated with their high viscosity, which affects mass transfer [13].

Because, to date, there is little information about the factors governing the low glycolipid yields obtained by DESs, the objective of this work was to evaluate, on a laboratory scale, the influence of five renewable deep eutectic solvents (Re-DESs) and two cosolvent reaction systems in the enzymatic synthesis of glycolipids via transesterification. The experimental set-up was designed to favor the synthesis by accounting for water inhibition (i.e., $R e$-DESs solvent and transesterification) and the heterogeneous nature of the reaction (i.e., the cosolvent system).

Previous studies have used lignocellulosic biomass as raw material to extract only the sugars required in the synthesis [14]. However, lignocellulosic biomass does not supply the two substrates required for the reaction. To supply both reaction substrates, i.e., sugars and fatty acids, we used peach palm fruit shell, an agricultural waste from southwestern Colombia, with a high content of carbohydrates (62.81\% wt) and lipids (13.47\% wt) [15], the use of sugars and fatty acids extracted from peach palm fruit shells for the enzymatic production of glycolipids was tested for the first time in this paper.

Finally, the synthesized glycolipid was physicochemically characterized to understand its functionality as a surfactant by measuring the surface tension change of aqueous solutions as a function of the biosurfactant concentration.

\section{Results and Discussion}

\subsection{Selection of Renewable Deep Eutectic Solvents (Re-DESs)}

Five types of Re-DESs were in-house synthesized from different hydrogen-bond donors (HBD) and choline chloride $(\mathrm{ChCl})$ as the hydrogen-bond acceptor (HBA). Once the solvents were formed, two model substrates (i.e., vinyl laurate and glucose) were added to the reaction media under continuous agitation and heating (Table 1). The main focus was on determining glucose solubilization (i.e., lack of a solid precipitate) and emulsifying of the lipidic substrate (i.e., one liquid phase).

Table 1. Qualitative evaluation of glucose solubility and emulsion formation with vinyl laurate using Re-DESs as solvent. HDB: hydrogen-bond donor.

\begin{tabular}{cccc}
\hline DES Label & HBD & Emulsion Formation & $\begin{array}{c}\text { Glucose } \\
\text { Precipitation }\end{array}$ \\
\hline$C h C l-G l c$ & Glucose (Glc) & - & - \\
$C h C l-L A$ & Lactic acid (LA) & - & - \\
$C h C l-G l y$ & Glycerol (Gly) & $\mathrm{X}$ & $\mathrm{X}$ \\
$C h C l-U$ & Urea & - & $\mathrm{X}$ \\
$C h C l-G l y-G l c$ & Glycerol and glucose & $\mathrm{X}$ & - \\
\hline
\end{tabular}

$\mathrm{X}$ : it means a positive response, and -: means a negative response to the evaluated criteria.

In the selection of Re-DESs, a favorable result implies (1) the nonprecipitation of glucose in the solvent, (2) emulsification and (3) lower viscosity (e.g., more favorable for mass transfer) in this heterogeneous catalytic reaction. According to the first criterion, $\mathrm{ChCl}$ Glc is an attractive option since it has been used simultaneously as a solvent and substrate to produce sugar-based surfactants $[5,10,16]$. However, the formation of an emulsion was not observed, and even at $70{ }^{\circ} \mathrm{C}$ and $1400 \mathrm{rpm}$, the $\mathrm{ChCl}-\mathrm{Glc}$ had a high viscosity (i.e., $4470 \mathrm{cP}$ ) [11]. Therefore, to decrease viscosity in the system, the temperature should be increased, compromising the biocatalyst stability. Another option is to add glycerol, which effectively decreases viscosity on DES [11]. For this reason, a Re-DES was prepared from glucose and glycerol, which showed a considerable decrease in viscosity compared to 
Re-DES prepared from glucose. Previous results have shown an important decrease in viscosity when glycerol was used, for instance, viscosity decreased for $\mathrm{ChCl}$ - $\mathrm{Glc}$ from 34,400 $\mathrm{cP}$ (without glycerol) to $930 \mathrm{cP}$ (with $50 \%$ molar of glycerol as $\mathrm{HBD}$ ), at $50{ }^{\circ} \mathrm{C}$ [11].

The second selection criterion is the formation of an emulsion between the Re-DES and vinyl laurate. Although the viscosity (third criterion) of DESs has been reported to be the most determining factor in the reaction $[10,14,17]$, when hydrophilic solvents are used, the total or partial insolubility of fatty acid esters is a persistent problem, which can affect glycolipid synthesis yields [18]. Therefore, Re-DESs that allow greater integration of vinyl laurate were selected, in this case (Table 1), ChCl-Gly and ChCl-Gly-Clc.

Nevertheless, due to their high polarity, by themselves, $\mathrm{ChCl}$-Gly and $\mathrm{ChCl}-\mathrm{Gly}$-Clc are deficient in facilitating the polar (sugars) and nonpolar (fatty acids) interactions necessary for catalyst contact to both substrates. As an alternative, the possibility of adding nonpolar (i.e., organic) solvents to the Re-DES was evaluated to integrate the phases of the heterogeneous media following previously reported results from a multiphase system using DES [19].

\subsection{Enzymatic Reaction System}

HPLC quantified glucose consumption and acetaldehyde formation (from the tautomerization of vinyl alcohol) to follow glycolipid formation in the reaction (Figure 1). However, the reaction conversion was reported based on glucose consumption because the acetaldehyde's volatility makes it difficult to measure its formation accurately.

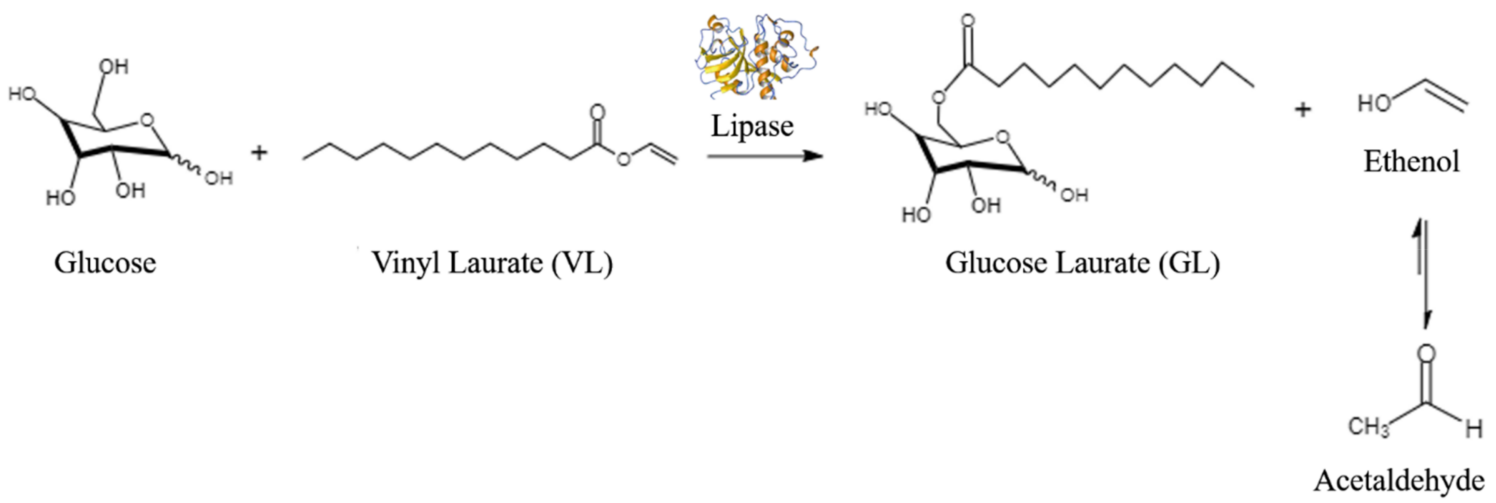

Figure 1. Formation of glucose laurate and vinyl alcohol from glucose and vinyl laurate.

\subsection{Enzymatic Synthesis of Glycolipids}

Three different reaction systems were prepared, using the selected Re-DESs, DMSO, and $t$-butanol (Table 2), to evaluate the influence of organic solvents in the heterogeneous media. In these systems, glycolipid synthesis (i.e., glucose laurate) was carried out through the catalytic action of a free enzyme or its immobilized version, under constant stirring and heating ( $500 \mathrm{rpm}$ and $50{ }^{\circ} \mathrm{C}$, respectively). The main result was to determine whether or not adding organic solvents improved the phase reaction of glucose (polar) and vinyl laurate (nonpolar) in Re-DESs medium (polar) and, consequently, favored conversion in the enzymatic reaction.

Table 2. Conversion (\%) in the transesterification of glucose and vinyl laurate, for four different reaction systems using Re-DESs and organic solvents. In all assays, the amount of enzyme necessary to contribute to $1595 \mathrm{U}$ was added.

\begin{tabular}{ccc}
\hline System Label & Enzyme & Conversion (\%) \\
\hline ChCl-Gly & Free & 3.72 \\
ChCl-Gly-Glc:t-butanol & Free & 3.25 \\
ChCl-Gly:DMSO:t-butanol & Free & 24.84 \\
$C h C l-G l y: D M S O: t-$ butanol & Immobilized & 21.01 \\
\hline
\end{tabular}


At $50^{\circ} \mathrm{C}$, the viscosity of $\mathrm{ChCl}-\mathrm{Gly}(64 \mathrm{cP})$ [20] facilitated the agitation and dispersion of substrates; however, the resulting conversion was low since part of the glucose precipitated and therefore was not available for reaction. At the same temperature, $\mathrm{ChCl}-\mathrm{Gly}$-Glc showed a higher viscosity $(930 \mathrm{cP})$ [11], and the system ChCl-Gly-Glc:t-butanol also presented a low conversion. The main reason for the low conversion in these systems can be associated with the higher viscosity and lower substrate availability, as the glucose was supplied as HBD and was less available for reaction, being trapped in the strong hydrogen bond network forming the DES [21].

Regarding the novel cosolvent system, ChCl-Gly:DMSO:t-butanol, the conversion achieved indicates that adding DMSO and $t$-butanol improved the glucose and vinyl laurate solubility in the medium. Although successful acylation reactions have been carried out in the bisolvent system DES: DMSO [22], it has not been tested as a reaction media in glycolipid synthesis. On the contrary, less than a 15\% conversion has been reported in other similar systems including or not cosolvent (Table 3).

Table 3. Conversion (\%) comparison on the transesterification of sugar and vinyl esters for glycolipid formation. For HBD, the molar ratio required per one mole of HBA is indicated in parentheses.

\begin{tabular}{|c|c|c|c|c|c|c|c|c|}
\hline \multirow{2}{*}{$\begin{array}{l}\text { Substrates (Acyl } \\
\text { Acceptor/Donor) }\end{array}$} & \multirow{2}{*}{ Enzyme } & \multicolumn{2}{|c|}{ Conditions } & \multirow{2}{*}{ Cosolvent } & \multicolumn{2}{|c|}{ DES } & \multirow{2}{*}{ Conversion (\%) } & \multirow{2}{*}{ Ref. } \\
\hline & & rpm & ${ }^{\circ} \mathrm{C}$ & & HBA & HBD & & \\
\hline \multirow{13}{*}{$\begin{array}{c}\text { Glucose/vinyl } \\
\text { laurate }\end{array}$} & \multirow{14}{*}{$\begin{array}{l}\text { Lipozyme } \\
\text { TLIM }\end{array}$} & \multirow{14}{*}{300} & \multirow{14}{*}{40} & \multirow{14}{*}{$\begin{array}{c}\text { 2-Methyl-2- } \\
\text { Butanone }(1: 9 v / v)\end{array}$} & \multirow{12}{*}{$\begin{array}{l}\text { Choline } \\
\text { Acetate (1) }\end{array}$} & Urea (2) & 3.26 & \multirow{14}{*}{ [13] } \\
\hline & & & & & & Urea (1) & 4.04 & \\
\hline & & & & & & Urea (0.5) & 13.09 & \\
\hline & & & & & & Acetamide (2) & 8.52 & \\
\hline & & & & & & Acetamide (1) & 5.54 & \\
\hline & & & & & & Acetamide (0.5) & 7.74 & \\
\hline & & & & & & Glycerol (2) & 6.46 & \\
\hline & & & & & & Glycerol (1) & 7.17 & \\
\hline & & & & & & Glycerol (0.5) & 9.02 & \\
\hline & & & & & & Ethylene Glycol (2) & 12.80 & \\
\hline & & & & & & Ethylene Glycol (1) & 10.52 & \\
\hline & & & & & & Ethylene Glycol (0.5) & 12.53 & \\
\hline & & & & & Choline & Urea (2) & 0.35 & \\
\hline & & & & & Chloride (1) & Glycerol (2) & 0.35 & \\
\hline $\begin{array}{l}\text { Glucose- } \\
\text { xylose/vinyl } \\
\text { octanoate }\end{array}$ & $\begin{array}{l}\text { Novozyme } \\
\quad 435\end{array}$ & 50 & 50 & - & $\begin{array}{l}\text { Choline } \\
\text { Chloride (1) }\end{array}$ & Sugar extract & 4.84 & [14] \\
\hline
\end{tabular}

In Table 3, we compiled the results reported in two studies in which DESs were used with either solvent or bi-solvent in the reaction. In both studies, the lower conversions obtained could be explain by an insufficient integration of the substrates to the medium, which affect the biocatalyst-substrate contact. On the other hand, the results in Table 2 show that the reaction media ChCl-Gly:DMSO:t-butanol was a more attractive option, which marked a path in the formulation of cosolvent systems to favor glycolipid synthesis by promoting glucose solubilization and availability (the main contribution of DMSO) and phase interaction with vinyl laurate (the main contribution of $t$-butanol). Thus, it was possible to propose a reaction media that would supply the specific task of synthesizing glycolipids with a higher conversion.

In the formulation of the proposed ternary system, it was considered that: (i) organic solvents with negative $\log p$ (polar solvents) interfere with lipase hydration, leaving them in an inactive form [23]. For this reason, tertiary alcohols such as $t$-butanol $(\log p 0.5)$ are more suitable since they provide high stability and enzymatic activity and present steric limitations that prevent them from being used as a substrate by the enzyme [17]. (ii) Contrary to what happens with organic solvents, some hydrophilic DESs favor the activity and stability of lipases [24-26]. Indeed, it was recently found that a greater portion of glycerol in DES increased the relative stability of the enzyme, compared to the behavior of the catalyst in ionic liquids [Bmim] [BF4] and acetone [27]. In conclusion, the conformed mixture of $t$-butanol, DMSO, and $\mathrm{ChCl}-\mathrm{Gly}$, under the evaluated conditions, favored 
reaction advance due to the increased interactions between phases and improved lipase stability in these nonconventional media.

In Table 2, a conversion of $21.01 \%$ was reached with the cosolvent system $\mathrm{ChCl}$ Gly:DMSO:t-butanol and the immobilized enzyme. Recent reports have demonstrated that for immobilized lipases exposed to reaction systems containing DES, their relative activities depend on three factors: (1) enzyme kind, (2) its immobilization support, and (3) DES composition [28]. For example, lipase from Candida antartica supported on the acrylic resin (recombinant, expressed in Aspergillus niger, the same used in this work) showed inhibition by glycerol-based DESs (e.g., involving factors 1 and 3 in the previous sentence). The inhibitory effect of glycerol-based DESs could be explained due to the change in polarity associated with the interactions between the terminal enzyme groups and the chemical nature of support. However, the main factor contributing to a lower conversion than the free enzyme on the same system label is immobilization support. The support creates an additional solid phase, further limiting mass transfer. Both substrates, glucose and vinyl laurate, should diffuse through the acrylic resin support to find the enzyme, react and the product should leave the support to allow new reactions. Diffusion of both substrates and product release from the catalyst support explained a lower conversion compared to the free enzyme.

\subsection{Enzymatic Synthesis of Glycolipids from Peach Palm Fruit Shells}

Once the cosolvent reaction system was defined, the aim was to evaluate a more sustainable process for glycolipid synthesis by using as substrates the sugars and fatty acids extracted from peach palm fruit shells. Regarding the lipidic fraction, the main fatty acids extracted from the agricultural residue were ( $>90 \%$ composition) oleic, palmitic, linoleic and palmitoleic acids (Table 4). Glucose was the main sugar obtained from the peach palm fruit shells by the enzymatic hydrolysis of its carbohydrates using amylases, cellulases, and hemicellulases (Table 5).

Table 4. Fatty acid composition of peach palm fruit shells.

\begin{tabular}{cc}
\hline Fatty Acid & \%wt \\
\hline Oleic acid & 39.42 \\
Palmitic acid & 29.30 \\
Linoleic acid & 13.88 \\
Palmitoleic acid & 8.26 \\
Y-Linolenic acid & 3.6 \\
Cis-9 Oleic acid & 2.34 \\
Stearic acid & 1.17 \\
Cis-13,16 Docosadienoic acid & 0.36 \\
Linolenic acid & 0.28 \\
Arachidonic acid & 0.25 \\
Cis-4,7,10,14,16,19 Docosahexaenoic acid & 0.20 \\
Myristic acid & 0.19 \\
Cis-10 Heptadecenoic acid & 0.18 \\
Cis-11 Eicosenoic acid & 0.17 \\
Heptadecanoic acid & 0.15 \\
Pentadecanoic acid & 0.13 \\
Cis-5,8,11,14,17 Eicosapentaenoic acid & 0.12 \\
\hline
\end{tabular}

Table 5. Composition of sugars in the hydrolysate stream from peach palm fruit shells.

\begin{tabular}{cc}
\hline Carbohydrate & \%wt \\
\hline Glucose & 94.17 \\
Galactose & 1.98 \\
Fructose & 1.72 \\
Arabinose & 1.47 \\
Sucrose & 0.67 \\
\hline
\end{tabular}


In this test, sugar hydrolysates were used in two modalities: (i) Re-DES was prepared from the sugars, glycerol, and choline chloride, which would function as the substrate and solvent at the same time. (ii) Additionally, for ChCl-Gly:DMSO:t-butanol system, the sugars were added as a free-substrate to the reaction media (Figure 2).

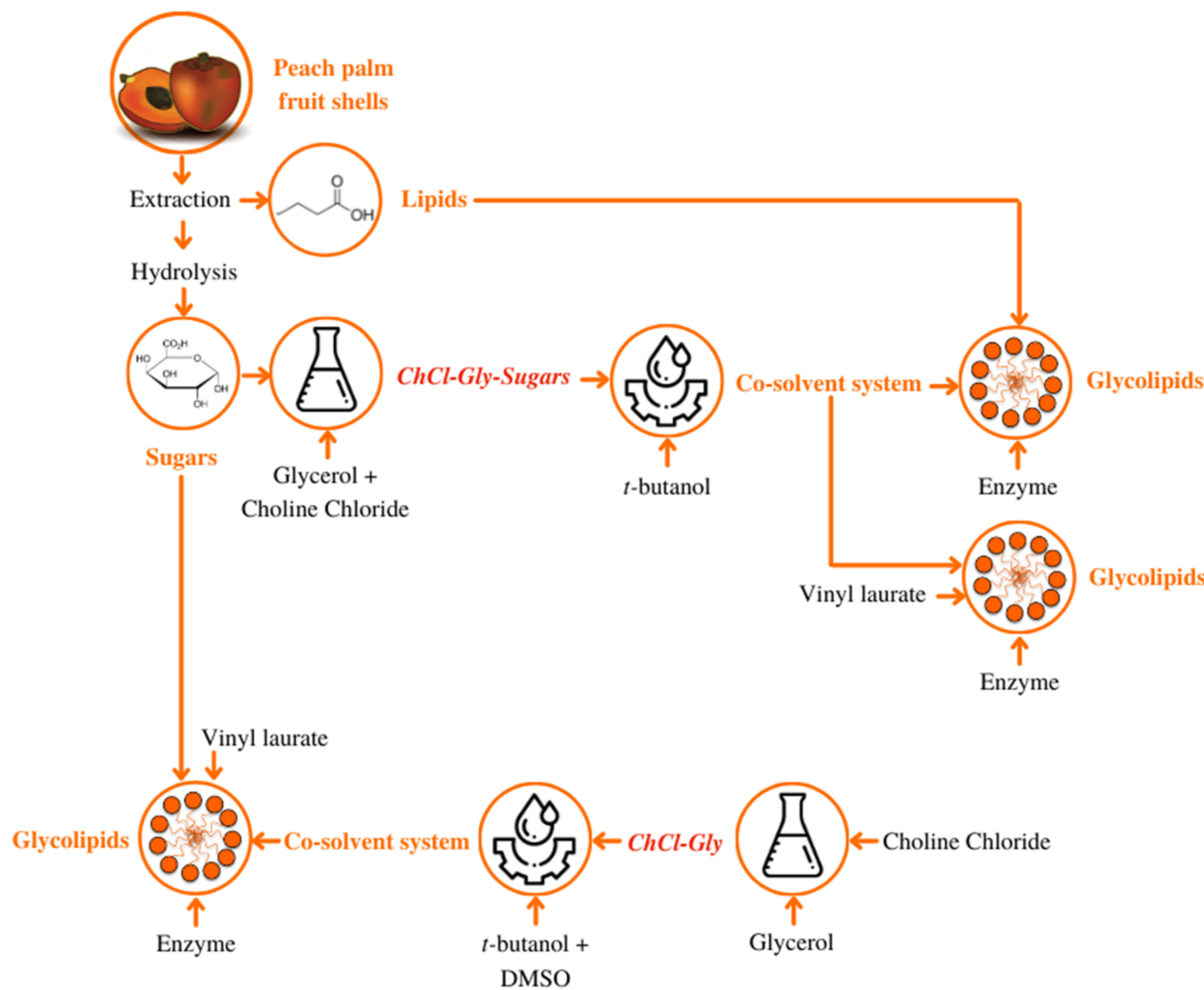

Figure 2. Global process scheme for the enzymatic production of glycolipids from sugars and lipids derived from peach palm fruit shell biorefining. In this study, sugars were supplied in two modalities: as part of the solvent (i.e., integrating the $R e$-DES) and as free-substrate.

The system ChCl-Gly-Sugars showed a low viscosity, attributable to glycerol in the mixture and water in the sugar stream used in the solvent formation. A similar case was reported by Siebenhaller and coworkers [29], where a DES, prepared from sugar hydrolysates of lignocellulosic biomass and choline chloride, presented a viscosity of $2.540 \mathrm{cP}$ at $50^{\circ} \mathrm{C}$, a much lower value if compared with the viscosity of DES from choline chloride and pure glucose $(34,400 \mathrm{cP})$ [11]. This decrease in viscosity, due to the water content in the Re-DES causes four times higher conversions achieved with ChCl-Gly-Sugars:tbutanol (Table 6) compared to ChCl-Gly-Glu:t-butanol.

Table 6. Conversion (\%) in the transesterification of sugars extracted from peach palm fruit shells and fatty acid or esters, using Re-DESs and organic solvents as reaction media. In all assays, the amount of enzyme necessary to contribute to $1595 \mathrm{U}$ was added.

\begin{tabular}{cccc}
\hline System Label & Fatty Acid or Ester & Enzyme & Conversion (\%) \\
\hline ChCl-Gly-Sugars:t-butanol & Vinyl laurate & Free & 13.06 \\
ChCl-Gly-Sugars:t-butanol & Lipid extract & Free & 0.18 \\
ChCl-Gly:DMSO:t-butanol & Vinyl laurate & Free & 23.84 \\
ChCl-Gly:DMSO:t-butanol & Vinyl laurate & Immobilized & 19.32 \\
\hline
\end{tabular}


In addition to affecting the DES viscosity [30-32], the water in the sugar stream can interact through hydrogen bonds with choline chloride (i.e., HBA) [33]. Because water can form hydrogen bonds with the HBA, it increases the sugar bioavailability for the reaction because it replaces the hydrogen bonds formed between the sugars and the HBA. If the hydrogen donor contains hydroxyl groups, a stronger interaction with the HBA is established, requiring a more significant amount of water to interrupt the association [30]. Therefore, as a strategy to improve the system, decrease viscosity, and increase the availability of sugars (i.e., the substrate), it is essential to determine the optimum water content that does not compromise the reaction equilibrium.

In the system ChCl-Gly-Sugars:t-butanol, a low conversion was obtained when using the lipidic extract from peach palm fruit shells as the presence of fatty acids promotes the formation of water throughout the reaction. Although water favors Re-DES by decreasing viscosity, an excess of it can lead to glycolipid hydrolysis. Therefore, it is suggested to esterificate the fatty acids to obtain fatty acid esters that will not release water throughout the reaction.

Conversely, a trend was observed in the conversion obtained in the treatments with ChCl-Gly:DMSO:t-butanol, using model compounds or the sugar extract. In this system, values close to $19 \%$ and $25 \%$ were reached, depending on whether an immobilized or free enzyme was used, which indicates that the formulated cosolvent is robust enough to facilitate mass transfer in the reaction when using a stream of single or various carbohydrates.

\subsection{Characterization of Synthesized Glycolipid}

The glucose-laurate molecule in the concentration range between $0.001 \%$ and $0.05 \%$ is in a free solution zone. The surfactant aggregation trend is almost null, due to the attraction between the molecules and the solvent media (Figure 3). For this reason, the observed changes in surface tension were minimal because the glycolipid molecules were distributed between the bulk medium and the air-water interphase. When increasing the surfactant concentration from $0.5 \%$ to $20 \%$, although the glucose laurate molecules were attracted to each other, the molecules mainly migrated to the air-water interphase. In this zone, surfactant molecules suffer a spatial rearrangement. They locate their hydrophobic tails towards the air and their hydrophilic heads in contact with the aqueous medium, forming a stable monolayer (zone of stability) [34]. This location or rearrangement process leads to a decrease in the water surface tension, indicating the glucose laurate tensioactivity. Finally, at higher surfactant concentration values $(20 \%$ and $40 \%)$, it can be observed that surface tension changes are trending to a constant zone. At this point, the glucose-laurate has saturated the air-water interphase. The excess molecules begin to be integrated into the medium in a thermodynamically more favorable conformation to avoid the hydrophobic effect between the tail and the water [35]. In this way, micelle formation occurs carrying the system to a considerable decrease in surface tension to $27.94 \mathrm{mN} / \mathrm{m}$. The concentration of $20 \%$, where micelle formation occurs, is called critical micellar concentration (CMC).

The discussion is also supported by the changing of the transversal area calculated using Gibb's excess function (Table 7), where it is observed that the transition between a free solution zone to a micellar formation zone indicates a diminishing in the interphase available area. In addition, the calculated values for the surface area were dynamic since the surfactant molecules were able to migrate between the interphase, the bulk aqueous medium and the micellar structure, while adopting a different configuration (Figure 3A).

Due to the concentration required to reach the micellar formation zone (Figure 3B), the studied glycolipid is an unattractive option as a foaming agent [36]. Even so, its nonionic nature and its hydrophobic tail give it an emulsifying capacity to reduce the surface tension between lipidic compounds and aqueous media. For this reason, glucose laurate is an alternative to alcohol ethoxylates, industrially produced at high temperatures to emulsify solutions. Thus, although sophisticated or straightforward chromatographic and spectrophotometric methods are the most widely used [37], measurement of surface 
tension, as a function of concentration, provided an approximation to the application of glucose laurate.

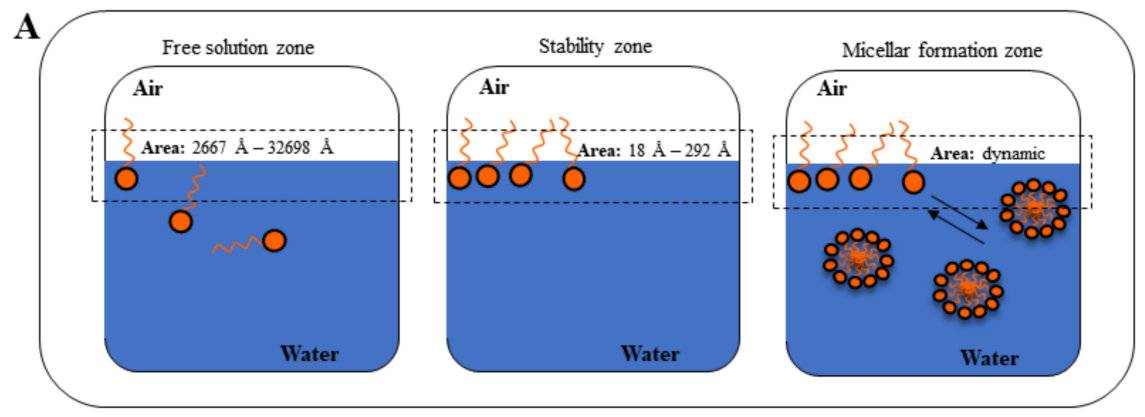

B

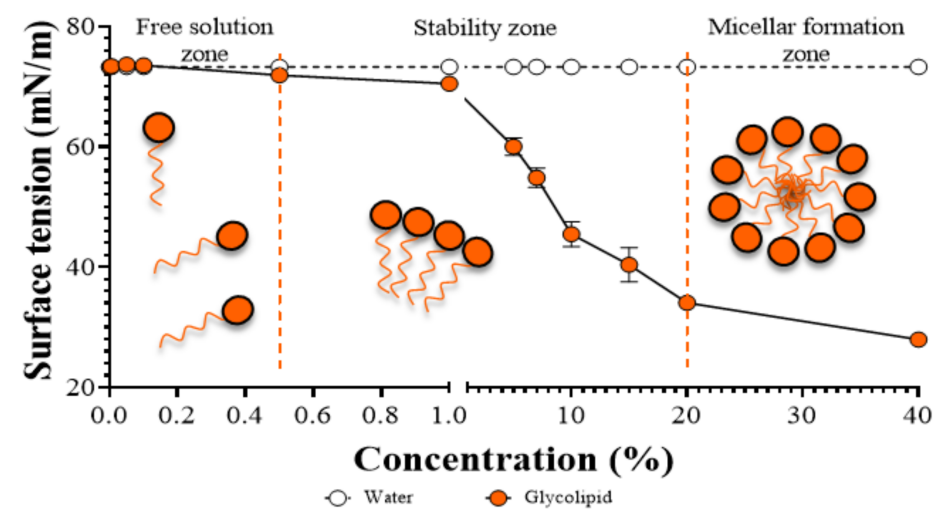

Figure 3. (A) Representation of the distribution of glucose laurate molecules in an aqueous solution. (B) Representation of the decrease in surface tension decrease when glucose laurate concentration increases.

Table 7. Values of surface tension, surface excess $(\Gamma)$, and area $(A)$ at different concentrations of the glycolipid in the aqueous solution.

\begin{tabular}{ccccccc}
\hline Concentration (\%) & Surface Tension (N/m) & $\mathbf{C} / \mathbf{R T}$ & $\mathbf{d} \gamma / \mathbf{d C}$ & $\Gamma\left(\mathbf{m o l} / \mathbf{m}^{\mathbf{2}}\right)$ & $\mathbf{A}\left(\mathbf{m}^{\mathbf{2}}\right)$ & $\mathbf{A}\left(\mathbf{\AA}^{\mathbf{2}}\right)$ \\
\hline 0.001 & 0.074 & $4.00 \times 10^{-7}$ & $-7.00 \times 10^{-2}$ & $3.00 \times 10^{-8}$ & $6.00 \times 10^{-17}$ & 5813.138 \\
0.005 & 0.073 & $2.00 \times 10^{-6}$ & $-3.00 \times 10^{-3}$ & $5.00 \times 10^{-9}$ & $3.00 \times 10^{-16}$ & $32,698.904$ \\
0.05 & 0.073 & $2.00 \times 10^{-5}$ & $-3.00 \times 10^{-3}$ & $6.00 \times 10^{-8}$ & $3.00 \times 10^{-17}$ & 2666.098 \\
0.5 & 0.072 & $2.00 \times 10^{-4}$ & $-3.00 \times 10^{-3}$ & $6.00 \times 10^{-7}$ & $3.00 \times 10^{-18}$ & 292.031 \\
1 & 0.070 & $4.00 \times 10^{-4}$ & $-3.00 \times 10^{-3}$ & $1.00 \times 10^{-6}$ & $2.00 \times 10^{-18}$ & 157.915 \\
5 & 0.060 & $2.00 \times 10^{-3}$ & $-3.00 \times 10^{-3}$ & $5.00 \times 10^{-6}$ & $3.00 \times 10^{-19}$ & 31.858 \\
7 & 0.055 & $3.00 \times 10^{-3}$ & $-3.00 \times 10^{-3}$ & $9.00 \times 10^{-6}$ & $2.00 \times 10^{-19}$ & 18.780 \\
10 & 0.045 & $4.00 \times 10^{-3}$ & $-1.00 \times 10^{-3}$ & $4.00 \times 10^{-6}$ & $4.00 \times 10^{-19}$ & 40.448 \\
15 & 0.040 & $6.00 \times 10^{-3}$ & $-1.00 \times 10^{-3}$ & $8.00 \times 10^{-6}$ & $2.00 \times 10^{-19}$ & 21.810 \\
20 & 0.034 & $8.00 \times 10^{-3}$ & $-3.00 \times 10^{-4}$ & $2.00 \times 10^{-6}$ & $7.00 \times 10^{-19}$ & 67.135 \\
\hline
\end{tabular}

\section{Materials and Methods}

\subsection{Materials}

Fungal mixture lipase (Lipomod 768) was purchased from Biocatalysts (Biocatalysts Inc., Chicago, IL, USA). Glucoamylase GA 300L was obtained from Proenzimas (Proenzimas SA, Cali, Colombia). Lipase expressed in Aspergillus niger (Lipase acrylic resin), $\alpha$-amylase Aspergillus oryzae, choline chloride (99.5\%), anhydrous glucose (99\%), lactic acid (88\%), urea (99\%), glycerol (99\%), t-butanol (99.5\%), ethanol $(99.8 \%)$, DMSO (99.9\%) and vinyl laurate (99\%) were provided by Sigma Aldrich (Sigma Aldrich, St. Louis, MI, USA). 


\subsection{Preparation of Re-DESs}

Five Re-DESs were prepared from choline chloride and different HBDs, in the molar ratios described in Table 8 . The mixtures were under constant stirring and heating $(500 \mathrm{rpm}$ and $70^{\circ} \mathrm{C}$ ) until a homogeneous liquid was generated. In the case $\mathrm{ChCl}-\mathrm{Glc}$, the heating temperature was increased to $100^{\circ} \mathrm{C}$ to promote solvent formation. Once the Re-DESs were synthesized, the moisture was removed from them in a vacuum oven (Labnet, Madrid, Spain) at $65^{\circ} \mathrm{C}$ and $0.08 \mathrm{Mbar}$ for $3 \mathrm{~h}$.

Table 8. Molar ratio between HBA (choline chloride: $\mathrm{ChCl}$ ) and the different HBDs (glucose: Glc, lactic acid: LA, glycerol: Gly, and urea: $\mathrm{U})$.

\begin{tabular}{cc}
\hline DES Label & Molar Ratio HBA:HBD \\
\hline ChCl-Glc & $1: 1$ \\
ChCl-LA & $1: 2$ \\
ChCl-Gly & $1: 2$ \\
ChCl-U & $1: 2$ \\
ChCl-Gly-Glc & $1: 0.5: 0.5$ \\
\hline
\end{tabular}

\subsection{Selection of Re-DESs}

A portion of $108.10 \mathrm{mg}$ of glucose and $135.82 \mathrm{mg}$ of vinyl laurate were added to $1.4 \mathrm{~mL}$ of each Re-DES. All assays were shaken and heated to $1400 \mathrm{rpm}$ and $50{ }^{\circ} \mathrm{C}$ on a MultiTherm shaker (Benchmark Scientific, New Jersey, USA). Best eutectic solvents were selected for use in the subsequent assays based on emulsion formation with vinyl laurate or glucose precipitation on the five Re-DESs tested.

\subsection{Enzymatic Synthesis of Glycolipid}

In $25 \mathrm{~mL}$ Schott bottles, $10 \mathrm{~mL}$ of the solvents or cosolvents (Table 9), $679 \mathrm{mg}$ of vinyl laurate, and $350 \mathrm{mg}$ of glucose were added, except for system ChCl-Gly-Glc:t-butanol, which integrated the carbohydrate as part of the solvent. A portion of $260 \mathrm{mg}$ of free enzyme or $319 \mathrm{mg}$ of immobilized enzyme was added, depending on the treatment to start the reaction. All assays were kept, for $48 \mathrm{~h}$, under constant conditions ( $500 \mathrm{rpm}$ and $50^{\circ} \mathrm{C}$ ) in an orbital shaker (Thermo Fisher Scientific, Waltham, MA, USA). As negative controls, reactions without vinyl laurate or enzyme were performed.

Table 9. Solvent or cosolvent reaction system used in glycolipid synthesis. The respective volumetric ratio is reported for the two systems formulated from the addition of organic solvents.

\begin{tabular}{cc}
\hline System Label & Volumetric Ratio \\
\hline ChCl-Gly & 1 \\
ChCl-Gly-Glc:t-butanol & $2: 3$ \\
ChCl-Gly:DMSO:t-butanol & $1: 1: 3$ \\
ChCl-Gly:DMSO:t-butanol & $1: 1: 3$ \\
\hline
\end{tabular}

\subsection{Enzymatic Synthesis of Glycolipids from Peach Palm Fruit Shells}

\subsubsection{Extraction of Lipids from Peach Palm Fruit Shells}

The peach palm fruit shell flour, previously dried and milled, was heated at $80{ }^{\circ} \mathrm{C}$ for $20 \mathrm{~min}$. Then, water was removed from the media, and ethanol (96\%) was added to extract the fatty acids from the flour. The extraction process was carried out for $1 \mathrm{~h}$ at $64^{\circ} \mathrm{C}$. Finally, the ethanol was evaporated to concentrate lipid extracts.

\subsubsection{Extraction of Sugars from Peach Palm Fruit Shells}

After the lipid extraction process, the degreased flour was mixed with phosphate buffer $(1: 15 p / p)$ and heated at $60^{\circ} \mathrm{C}$ for $10 \mathrm{~min}$. Then, three sequential reactions were carried out: (1) The holocellulose present in the vegetable residue was hydrolyzed by 
adding the Viscozyme L complex. (2) The enzyme $\alpha$-amylase was added to break the bonds in the starch. (3) Simple sugars were obtained by the catalytic action of the enzyme glucoamylase GA $300 \mathrm{~L}$. The operating conditions set are reported in Table 10.

Table 10. Operational conditions for each stage of the extraction of sugars from peach palm fruit shells. All enzymatic reactions are maintained at a $\mathrm{pH}$ equal to 5.

\begin{tabular}{ccc}
\hline Enzyme & Temperature $\left({ }^{\circ} \mathbf{C}\right)$ & Reaction Time $(\mathbf{m i n})$ \\
\hline Viscozyme & 50 & 120 \\
$\alpha$-amylase & 55 & 120 \\
Glucoamylase & 55 & 60 \\
\hline
\end{tabular}

The sugar extract was centrifuged to separate the flour from liquid media, and the supernatant was concentrated in a rotary evaporator (BUCHI, Barcelona, Spain). Finally, the quantification of the concentrated stream was carried out by HPLC.

\subsubsection{Enzymatic Synthesis of Glycolipids from Peach Palm Fruit Shells}

To act simultaneously as substrate, the Re-DES ChCl-Gly-Sugars were formed from choline chloride, glycerol, and the concentrated stream of sugars (1:0.5:0.5 molar ratio). The $R e$-DES prepared was mixed with $t$-butanol, maintaining the volumetric ratio specified in Table 11.

Table 11. Assays prepared in the cosolvent system ChCl-Gly-Sugars:t-butanol and ChCl-Gly:DMSO:t-butanol to synthesize glycolipids using peach palm fruit shells-extracts.

\begin{tabular}{|c|c|c|c|c|c|}
\hline \multirow{2}{*}{ System Label } & \multirow{2}{*}{ Volumetric Ratio } & \multirow{2}{*}{ Enzyme Mass (mg) } & \multicolumn{3}{|c|}{ Substrates } \\
\hline & & & Sugar Extract ${ }^{3}(\mathrm{~mL})$ & Vinyl Laurate (mg) & Lipidic Extract (mL) \\
\hline ChCl-Gly-Sugars:t-butanol ${ }^{1}$ & $2: 3$ & 260 & - & 679 & - \\
\hline ChCl-Gly-Sugars:t-butanol ${ }^{1}$ & $2: 3$ & 260 & - & - & 0.78 \\
\hline ChCl-Gly:DMSO:t-butanol ${ }^{1}$ & $1: 1: 3$ & 260 & 1.19 & 679 & - \\
\hline ChCl-Gly:DMSO:t-butanol ${ }^{2}$ & $1: 1: 3$ & 319 & 1.19 & 679 & - \\
\hline
\end{tabular}

${ }^{1}$ Free enzyme. ${ }^{2}$ Immobilized enzyme. ${ }^{3}$ Sugar concentration of $294.97 \mathrm{~g} / \mathrm{L}$.

From the cosolvents ChCl-Gly-Sugars:t-butanol and ChCl-Gly:DMSO:t-butanol, four assays were prepared with $10 \mathrm{~mL}$ of the reaction media. After adding the substrate and observing homogeneity in each system, the reaction was started with the enzyme addition. For $48 \mathrm{~h}$, the conditions were maintained at $50{ }^{\circ} \mathrm{C}$ and $950 \mathrm{rpm}$, using a heating plate equipped with a magnetic stirrer (Thermo Fisher Scientific, Waltham, MA, USA). Negative controls were prepared without vinyl laurate or enzyme.

\subsection{Analytical Method to Follow the Reaction}

The samples were diluted in water $(1: 10 v / v)$ to measure the sugar consumption and acetaldehyde coproduction by analyzing in HPLC (Thermo Fisher Scientific, Waltham, MA, USA), using an Aminex HPX-87H column (Biorad) and both a RI and DAD detector. In this analysis, sulfuric acid solution $(5 \mathrm{mM})$ was used as a mobile phase with a flow rate of $0.6 \mathrm{~mL} / \mathrm{min}$, operating at $65^{\circ} \mathrm{C}$. Five solutions with different concentrations of glucose, fructose, glycerol, and acetaldehyde were injected as standards.

\subsection{Characterization of the Synthesized Glycolipid}

First, an extraction was realized to carry out the characterization of glucose laurate, diluting the medium in hot distilled water $\left(70^{\circ} \mathrm{C}\right)$ and, subsequently, adding ethyl acetate $(1: 1 \mathrm{v} / \mathrm{v})$. After vigorous stirring for $1 \mathrm{~min}$, the organic phase was separated and concentrated in a vacuum oven (Labnet, Madrid, Spain) at $50{ }^{\circ} \mathrm{C}$ and $0.08 \mathrm{Mbar}$. The glycolipid extracted with ethyl acetate was resuspended in ethanol and diluted in water to prepare dilutions between $0.001 \%$ and $40 \% v / v$. For each dilution, the change in the surface tension 
of an aqueous medium was measured as a function of the concentration of the synthesized glucose laurate. The surface tension was measured by the pendant drop method using a contact angle meter (OCA15EC Dataphysics Instruments, Filderstadt, Germany) with a software driver (version 4.5.14 SCA20, SCA Software, Stockholm, Sweden). Measurements were made in triplicate at $25{ }^{\circ} \mathrm{C}$ and $65 \%$ of relative humidity.

From the surface tension values, the surface excess $(\Gamma)$ was calculated with the Gibbs adsorption isotherm equation (Equation (1)) [34] and, in addition, the area (A) (Equation (2)) [38].

$$
\begin{gathered}
\Gamma=\frac{\mathrm{C}}{\mathrm{RT}}\left(\frac{d \gamma}{d \mathrm{C}}\right) \\
\mathrm{A}=\frac{1}{\Gamma \mathrm{N}_{\mathrm{A}}}
\end{gathered}
$$

where $\gamma$ corresponds to the surface tension of the solution $(\mathrm{N} / \mathrm{m}), \Gamma$ is the excess surface $\left(\mathrm{mol} / \mathrm{m}^{2}\right), \mathrm{A}$ is the area $\left(\mathrm{m}^{2}\right), \mathrm{C}$ is the concentration of the glycolipid $(\mathrm{M}), \mathrm{R}$ is the gas constant $(8.314 \mathrm{~J} / \mathrm{mol} \mathrm{K}), \mathrm{T}$ is the temperature $(\mathrm{K})$ and $\mathrm{N}_{\mathrm{A}}$ is Avogadro's number.

\section{Conclusions}

In this study, the novel cosolvent system (ChCl-Gly:DMSO:t-butanol) favored glycolipid synthesis by improving biocatalyst contact with glucose and vinyl laurate, in addition to facilitating mass transfer, due to its lower viscosity. As a result, the cosolvent allowed a conversion of $24.84 \%$ to be reached, the highest value reported to date in the production of glycolipids on DES.

ChCl-Gly:DMSO:t-butanol was also used to synthesize glycolipids using both sugars and fatty acids extracted from a single agricultural residue: peach palm fruit shells. With a conversion of $23.84 \%$, it was demonstrated that it is possible to use residual biomass as raw material to carry out a sustainable production process for glycolipids using a single source for both required substrates.

It was also demonstrated that the cosolvent system ChCl-Gly:DMSO:t-butanol was robust enough to facilitate the enzymatic synthesis of glycolipids using model compounds or sugar and fatty acids extracts with conversion values ranging from $19-25 \%$ depending on whether an immobilized or free enzyme was used.

Finally, the glycolipid formed from vinyl laurate and glucose was characterized, establishing the surface tension at the water-air interface as a criterion. In an aqueous solution with a concentration of $40 \% v / v$ of the glycolipid, the surface tension was reduced to $27.94 \mathrm{mN} / \mathrm{m}$. This remarkable reduction, added to its nonionic nature, makes glucose laurate an alternative to traditional emulsifiers, such as alcohol ethoxylates.

Author Contributions: Conceptualization, C.A.-V. and N.H.C.O.; data curation, L.V.H. and L.R.; funding acquisition, N.H.C.O.; investigation, L.V.H. and L.R.; methodology, C.A.-V., C.J.Y. and N.H.C.O.; writing-original draft, L.V.H. and L.R.; writing-review and editing, C.A.-V. and N.H.C.O.; supervision, C.A.-V., C.J.Y. and N.H.C.O. All authors have read and agreed to the published version of the manuscript.

Funding: All the Budget came from Universidad ICESI pilot plant development project "BioprodPacific".

Data Availability Statement: The data presented in this study are available on request from the corresponding author. The data are not publicly available due to an industrial secret.

Acknowledgments: The authors acknowledge the significant laboratory support from Biochemical Engineering students: Jose David Gómez, Maria Paula Sarria and Frank Ávila. We acknowledge the key orientation from Erika Ortiz and Andrés Ceballos.

Conflicts of Interest: The authors declare no conflict of interest. 


\section{References}

1. Boxley, C.J.; Pemberton, J.E.; Maier, R.M. Rhamnolipids and Related Biosurfactants for Cosmetics and Cosmeceutical Markets. Int. News Fats Oils Relat. Mater. 2015, 26, 206-215. [CrossRef]

2. Shu, Q.; Lou, H.; Wei, T.; Liu, X.; Chen, Q. Contributions of Glycolipid Biosurfactants and Glycolipid-Modified Materials to Antimicrobial Strategy: A Review. Pharmaceutics 2021, 13, 227. [CrossRef]

3. Šabeder, S.; Habulin, M.; Knez, Ž. Lipase-Catalyzed Synthesis of Fatty Acid Fructose Esters. J. Food Eng. 2006, 77, 880-886. [CrossRef]

4. Abdulmalek, E.; Hamidon, N.F.; Abdul Rahman, M.B. Optimization and Characterization of Lipase Catalysed Synthesis of Xylose Caproate Ester in Organic Solvents. J. Mol. Catal. B Enzym. 2016, 132, 1-4. [CrossRef]

5. Pöhnlein, M.; Ulrich, J.; Kirschhöfer, F.; Nusser, M.; Muhle-Goll, C.; Kannengiesser, B.; Brenner-Weiß, G.; Luy, B.; Liese, A.; Syldatk, C.; et al. Lipase-Catalyzed Synthesis of Glucose-6-O-Hexanoate in Deep Eutectic Solvents. Eur. J. Lipid Sci. Technol. 2015, 117, 161-166. [CrossRef]

6. Durand, E.; Lecomte, J.; Baréa, B.; Piombo, G.; Dubreucq, E.; Villeneuve, P. Evaluation of Deep Eutectic Solvents as New Media for Candida Antarctica B Lipase Catalyzed Reactions. Process Biochem. 2012, 47, 2081-2089. [CrossRef]

7. Neta, N.S.; Teixeira, J.A.; Rodrigues, L.R. Sugar Ester Surfactants: Enzymatic Synthesis and Applications in Food Industry. Crit. Rev. Food Sci. Nutr. 2015, 55, 595-610. [CrossRef]

8. Paiva, A.; Craveiro, R.; Aroso, I.; Martins, M.; Reis, R.L.; Duarte, A.R.C. Natural Deep Eutectic Solvents-Solvents for the 21st Century. ACS Sustain. Chem. Eng. 2014, 2, 1063-1071. [CrossRef]

9. Chanquia, S.N.; Huang, L.; Liñares, G.G.; de María, P.D.; Kara, S. Deep Eutectic Solvents as Smart Cosubstrate in Alcohol Dehydrogenase-Catalyzed Reductions. Catalysts 2020, 10, 1013. [CrossRef]

10. Siebenhaller, S.; Muhle-Goll, C.; Luy, B.; Kirschhöfer, F.; Brenner-Weiss, G.; Hiller, E.; Günther, M.; Rupp, S.; Zibek, S.; Syldatk, C. Sustainable Enzymatic Synthesis of Glycolipids in a Deep Eutectic Solvent System. J. Mol. Catal. B Enzym. 2016, 133, S281-S287. [CrossRef]

11. Maugeri, Z.; Domínguez De María, P. Novel Choline-Chloride-Based Deep-Eutectic-Solvents with Renewable Hydrogen Bond Donors: Levulinic Acid and Sugar-Based Polyols. RSC Adv. 2012, 2, 421-425. [CrossRef]

12. Markiewicz, M.; Piszora, M.; Caicedo, N.; Jungnickel, C.; Stolte, S. Toxicity of Ionic Liquid Cations and Anions towards Activatedsewage Sludge Organisms from Different Sources-Consequences for Biodegradation Testing Andwastewater Treatment Plant Operation. Water Res. 2013, 47, 2921-2928. [CrossRef]

13. Zhao, K.H.; Cai, Y.Z.; Lin, X.S.; Xiong, J.; Halling, P.J.; Yang, Z. Enzymatic Synthesis of Glucose-Based Fatty Acid Esters in Bisolvent Systems Containing Ionic Liquids or Deep Eutectic Solvents. Molecules 2016, 21, 1294. [CrossRef]

14. Siebenhaller, S.; Hajek, T.; Muhle-Goll, C.; Himmelsbach, M.; Luy, B.; Kirschhöfer, F.; Brenner-Weiß, G.; Hahn, T.; Zibek, S.; Syldatk, C. Beechwood Carbohydrates for Enzymatic Synthesis of Sustainable Glycolipids. Bioresour. Bioprocess 2017, 4. [CrossRef] [PubMed]

15. Martínez, J.; Rodríguez, X.; Pinzón, L.; Ordóñez, L.E. Caracterización Fisicoquímica de Harina de Residuos Del Fruto de Chontaduro (Bactris Gasipaes Kunth, Arecaceae) Obtenida Por Secado Convectivo. Physicochemical Characterization of the Peach Palm (Bactris Gasipaes Kunth, Arecaceae) Fruit Skin Residue. Cienc. Tecnol. Agropecu. 2017, 18, 599-613. [CrossRef]

16. Siebenhaller, S.; Gentes, J.; Infantes, A.; Muhle-Goll, C.; Kirschhöfer, F.; Brenner-Weiß, G.; Ochsenreither, K.; Syldatk, C. LipaseCatalyzed Synthesis of Sugar Esters in Honey and Agave Syrup. Front. Chem. 2018, 6, 1-9. [CrossRef]

17. Siebenhaller, S.; Grüninger, J.; Syldatk, C. Enzymatic Synthesis of Glycolipid Surfactants. In Lipid Modification by Enzymes and Engineered Microbes; Elsevier: Amsterdam, The Netherlands, 2018; pp. 293-313. [CrossRef]

18. Hollenbach, R.; Bindereif, B.; van der Schaaf, U.S.; Ochsenreither, K.; Syldatk, C. Optimization of Glycolipid Synthesis in Hydrophilic Deep Eutectic Solvents. Front. Bioeng. Biotechnol. 2020, 8, 1-10. [CrossRef] [PubMed]

19. Lang, J.; Lu, J.; Lan, P.; Wang, N.; Yang, H.; Zhang, H. Preparation of 5-HMF in a Des/Ethyl n-Butyrate Two-Phase System. Catalysts 2020, 10, 636. [CrossRef]

20. Abbott, A.P.; Harris, R.C.; Ryder, K.S.; D’Agostino, C.; Gladden, L.F.; Mantle, M.D. Glycerol Eutectics as Sustainable Solvent Systems. Green Chem. 2011, 13, 82-90. [CrossRef]

21. Durand, E.; Lecomte, J.; Baréa, B.; Dubreucq, E.; Lortie, R.; Villeneuve, P. Evaluation of Deep Eutectic Solvent-Water Binary Mixtures for Lipase-Catalyzed Lipophilization of Phenolic Acids. Green Chem. 2013, 15, 2275-2282. [CrossRef]

22. Cao, S.L.; Deng, X.; Xu, P.; Huang, Z.X.; Zhou, J.; Li, X.H.; Zong, M.H.; Lou, W.Y. Highly Efficient Enzymatic Acylation of Dihydromyricetin by the Immobilized Lipase with Deep Eutectic Solvents as Cosolvent. J. Agric. Food Chem. 2017, 65, $2084-2088$. [CrossRef]

23. Yadav, G.D.; Lathi, P.S. Synthesis of Citronellol Laurate in Organic Media Catalyzed by Immobilized Lipases: Kinetic Studies. J. Mol. Catal. B Enzym. 2004, 27, 113-119. [CrossRef]

24. Kim, S.H.; Park, S.; Yu, H.; Kim, J.H.; Kim, H.J.; Yang, Y.H.; Kim, Y.H.; Kim, K.J.; Kan, E.; Lee, S.H. Effect of Deep Eutectic Solvent Mixtures on Lipase Activity and Stability. J. Mol. Catal. B Enzym. 2016, 128, 65-72. [CrossRef]

25. Durand, E.; Lecomte, J.; Villeneuve, P. Deep Eutectic Solvents: Synthesis, Application, and Focus on Lipase-Catalyzed Reactions. Eur. J. Lipid Sci. Technol. 2013, 115, 379-385. [CrossRef]

26. Huang, Z.L.; Wu, B.P.; Wen, Q.; Yang, T.X.; Yang, Z. Deep Eutectic Solvents Can Be Viable Enzyme Activators and Stabilizers. J. Chem. Technol. Biotechnol. 2014, 89, 1975-1981. [CrossRef] 
27. Oh, Y.; Park, S.; Yoo, E.; Jo, S.; Hong, J.; Kim, H.J.; Kim, K.J.; Oh, K.K.; Lee, S.H. Dihydrogen-Bonding Deep Eutectic Solvents as Reaction Media for Lipase-Catalyzed Transesterification. Biochem. Eng. J. 2019, 142, 34-40. [CrossRef]

28. Elgharbawy, A.A.; Hayyan, A.; Hayyan, M.; Rashid, S.N.; Nor, M.R.M.; Zulkifli, M.Y.; Alias, Y.; Mirghani, M.E.S. Shedding Light on Lipase Stability in Natural Deep Eutectic Solvents. Chem. Biochem. Eng. Q. 2018, 32, 359-370. [CrossRef]

29. Siebenhaller, S.; Kirchhoff, J.; Kirschhöfer, F.; Brenner-Weiß, G.; Muhle-Goll, C.; Luy, B.; Haitz, F.; Hahn, T.; Zibek, S.; Syldatk, C.; et al. Integrated Process for the Enzymatic Production of Fatty Acid Sugar Esters Completely Based on Lignocellulosic Substrates. Front. Chem. 2018, 6, 1-11. [CrossRef]

30. Cvjetko Bubalo, M.; Jurinjak Tušek, A.; Vinković, M.; Radošević, K.; Gaurina Srček, V.; Radojčić Redovniković, I. Cholinium-Based Deep Eutectic Solvents and Ionic Liquids for Lipase-Catalyzed Synthesis of Butyl Acetate. J. Mol. Catal. B Enzym. 2015, 122, 188-198. [CrossRef]

31. Guajardo, N.; Ahumada, K.; Domínguez de María, P. Immobilized Lipase-CLEA Aggregates Encapsulated in Lentikats®as Robust Biocatalysts for Continuous Processes in Deep Eutectic Solvents. J. Biotechnol. 2020, 310, 97-102. [CrossRef]

32. Guajardo, N.; Domínguez de María, H.P.; Ahumada, K.; Schrebler, R.A.; Ramírez-Tagle, R.; Crespo, F.A.; Carlesi, C. Water as Cosolvent: Nonviscous Deep Eutectic Solvents for Efficient Lipase-Catalyzed Esterifications. Chem CatChem 2017, 9, 1393-1396. [CrossRef]

33. Choi, Y.H.; Van Spronsen, J.; Dai, Y.; Verberne, M.; Hollmann, F.; Arends, I.W.C.E.; Witkamp, G.-J.; Verpoorte, R. Scientific Correspondence. Are Natural Deep Eutectic Solvents the Missing Link in Understanding Cellular Metabolism and Physiology? Plant Physiol. 2011, 156, 1701-1705. [CrossRef] [PubMed]

34. Persson, C.M.; Kjellin, U.R.M.; Eriksson, J.C. Surface Pressure Effect of Poly(Ethylene Oxide) and Sugar Headgroups in LiquidExpanded Monolayers. Langmuir 2003, 19, 8152-8160. [CrossRef]

35. Lombardo, D.; Kiselev, M.A.; Magazù, S.; Calandra, P. Amphiphiles Self-Assembly: Basic Concepts and Future Perspectives of Supramolecular Approaches. Adv. Condens. Matter Phys. 2015. [CrossRef]

36. Blecker, C.; Piccicuto, S.; Lognay, G.; Deroanne, C.; Marlier, M.; Paquot, M. Enzymatically Prepared N-Alkyl Esters of Glucuronic Acid: The Effect of Hydrophobic Chain Length on Surface Properties. J. Colloid Interface Sci. 2002, 247, 424-428. [CrossRef]

37. Varjani, S.J.; Upasani, V.N. Critical Review on Biosurfactant Analysis, Purification and Characterization Using Rhamnolipid as a Model Biosurfactant. In Bioresource Technology; Elsevier Ltd.: Amsterdam, The Netherlands, 2017; pp. 389-397. [CrossRef]

38. Zhang, X.; Song, F.; Taxipalati, M.; Wei, W.; Feng, F. Comparative Study of Surface-Active Properties and Antimicrobial Activities of Disaccharide Monoesters. PLoS ONE 2014, 9, e0114845. [CrossRef] [PubMed] 